\title{
Understanding demand and supply paradoxes and their role in business-to-business firms
}

\section{Introduction}

Firms' marketing and supply chain management (SCM) functions face the challenge of developing simultaneously efficient and effective demand and supply systems, as demand and supply activities take different routes to creating value for customers and firms. Despite the major advances in technology and managerial competence, the fragmented approaches to and tensions between firms' demand and supply activities continue to be a grave practical problem (Tate et al., 2015). This reality requires finding innovative and subtle ways of collaboration to transcend tensions and disconnects between demand and supply activities that may arise as a serious paradox (Hung, 2010). However, empirical research on how the relationship between demand and supply activities unfolds in the face of their paradoxical entwinement is scant and formulaic (Esper et al., 2010; Jüttner, Christopher, \& Godsell, 2010; Santos \& D'Antone, 2014). The question of why the great divide between demand and supply persists in many firms (Drucker, 1973) remains unsolved, despite the logical appeal of and facilitative means for their integration.

Understanding and managing the paradox of demand and supply is important as the world becomes more dynamic and complex. Creating relevant stakeholder value may distinctly rely on success in managing paradoxical strategies holistically when firms face economic volatility, customer demand instability, inventory write-offs, and supply chain fluctuations (Smith, Binns, \& Tushman, 2010). Firms that can transcend these paradoxes achieve reliable and adaptive supply chains, real-time demand insights, and accelerated decision-making; which result in high growth and profitability. On the other hand, firms that are trapped in these paradoxes end up in a range of problems including material shortages, excessive and costly inventory, poor customer service, and cash flow difficulties. Thus, in this paper, we endeavor to understand different types of demand and supply paradoxes as paradoxes firms face at their demand-supply interface, and how firms engage in a delicate and constant struggle to transcend these paradoxes. 
An increasingly important angle that can help understand demand and supply as organic and sophisticated processes but has not yet been utilized to address tensions between demand and supply is paradox theory (Schad et al., 2016). Academics and practitioners increasingly adopt paradox theory to understand and explain tensions and contradictory demands faced in the dynamic and competitive marketplace (Smith \& Lewis, 2011). Paradox theory's exploration of how firms can attend to competing demands simultaneously can help minimize the missed opportunities resulting from favoring either demand or supply at the expense of the other (Tate et al., 2015). Accordingly, paradox theory is a strong candidate to shed some light on the persistent conundrum of demand and supply tensions and their ensuing paradoxes.

The major thrust of this study is to explore the influence of demand and supply paradoxes on the relationships between B2B firms' demand and supply activities. We inquire how managers make sense of and deal with paradoxes they experience at the demand-supply interface (DSI)- the point of encounter between functions, activities, and actors involved in demand and supply (Santos \& D'Antone, 2014). In the pursuit of our purpose, we investigate the following overall research question: How do B2B firms face, manage, and transcend paradoxes related to their demand and supply activities? Because this subject remains underexplored and entails complex social processes involving people and their behaviors, we fulfill the research objective via qualitative research.

Our findings illuminate the nature of demand and supply paradoxes and how B2B firms' experiences of facing, and managing, transcending these paradoxes shape the activities and relationships at DSI. In particular, we reveal that marketing and SCM managers can experience ambivalence and avoidance when facing demand and supply paradoxes that encompass salient categories of collaboration-competition, concord-conflict, and integration-differentiation. We also find that marketing and SCM managers' amplifying or balancing these paradoxes shape the way demand and supply activities are interlinked. Furthermore, our results show that though reframing and transcending these paradoxes require creative third-way approaches, it can markedly improve the potential synergy between demand and supply activities. 
We contribute to research on $\mathrm{B} 2 \mathrm{~B}$ marketing strategy and organizational design. We incorporate a paradox theory into DSI to advance the understanding of how demand and supply paradoxes are at the epicenter of successful marketing strategy. We define demand and supply paradox as the simultaneous and persisting existence of harmony and tension in the organizational structures and relationships of B2B firms regarding their demand and supply activities. Our dynamic model of demand and supply paradoxes and their effect illustrates how B2B firms experience and deal with competing demands of and tensions between demand and supply activities simultaneously and rise above ensuing demand and supply paradoxes to create better value. In doing so, we offer an empirical account of the intriguing discrepancy between the theory and practice concerning the management of demand and supply (Jüttner, Christopher, \& Baker, 2007; Tate et al., 2015).

\section{Theoretical background}

\subsection{Demand and supply activities and their interface}

There are multiple means to create value. Though creating value is the common end for both marketing and SCM functions (Mentzer, Stank, \& Esper, 2008), the means through which value is created often involve divergent approaches. Tasked primarily with creating demand, marketing function typically emphasizes the benefits side of the value equation (Hung, 2010; Santos \& D'Antone, 2014). Marketing-driven firms concentrate on satisfying customers through benefits they deliver, sometimes at the expense of firms' overall interests (Esper et al., 2010; Oliver, 2004; Tate et al., 2015). However, tasked primarily with supply (i.e., fulfilling demand), SCM function often pays higher attention to costs side of the value equation (Fugate, Mentzer, \& Stank, 2010; Santos \& D'Antone, 2014). SCM-driven firms follow cost leadership and product-centric strategies as means of creating and providing value (Chatain, 2011; Esper et al., 2010; Fugate et al., 2010). These two alternative approaches are co-existing blueprints for value creation (Smith et al., 2010).

Demand and supply activities are interdependent business processes that are mainly immersed in the respective functions of marketing and SCM (Santos \& D'Antone, 2014). Demand activities are about identifying, creating, fostering, and communicating customer want for firms' products and 
services. They include market opportunity assessment, customer value assessment, customer communications, advertising, sales, and branding (Mentzer et al., 2008). Demand activities often focus on differentiation, economies of scope, market expansion, and effectiveness. Alternatively, supply activities are about fulfill existing customer demand for firms' products and services (Hung, 2010). They include manufacturing, procurement, inventory management, logistics, order management \& fulfillment, and supply chain coordination (Mentzer et al., 2008). Supply activities often focus on standardization, economies of scale, market appropriation, and efficiency (Esper et al., 2010; Hung, 2010). Such divergent approaches toward and competing priorities for creating value through demand and supply result in challenging and paradoxical managerial problems (Hung, 2010) and sub-optimal customer solutions (Tate et al., 2015).

\subsection{Demand and supply paradoxes}

In the fabric of daily life, the relationship between demand and supply activities is far beyond being clear-cut and is laden with paradoxes. Despite substantial interaction with each other and intuitive appeal of integration, marketing and SCM are rarely natural allies, as they hold different values and objectives (Jüttner et al., 2010). Moreover, in many firms, marketing and SCM functions are seen as "profit centers" that compete for increased organizational clout (Tsai, 2002). The subsequent myopic mindset of managers who concentrate only on one side can result in unintended tensions and subpar outcomes (Hung, 2010; Paquin, Busch, \& Tilleman, 2015). Therefore, these functions can be inherently, even if inadvertently, dysfunctional (Malshe, Johnson, \& Viio, 2017; Tsai, 2002).

Tensions at DSI may persist even if demand and supply activities are not inherently contradictory. Managers trying to do their delineated tasks while other people in the firm have different tasks with different objectives to get on with can engender tensions. Moreover, firms' organizational contexts are not free from power dynamics and ensuing tensions among functions as well as activities (Astley \& Sachdeva, 1984; Corvellec \& Hultman, 2014). Consequently, we argue that such discrepancy between the theory and practice of demand and supply is puzzling and multidimensional, and paradox theory can help explain this conundrum. 
Paradox theory focuses on examining the multifaceted and dialectic nature of organizational dynamics and managerial action. It has gained prominence for research seeking out insights into the nature and management of conflicting demands to explain a broad range of business phenomena that take place in increasingly volatile and complicated environments (Putnam, Fairhurst, \& Banghart, 2016; Schad et al., 2016). It helps build a realistic picture of modern socioeconomic phenomena that are convoluted and multifaceted (Putnam et al., 2016). It offers organizational practitioners a useful conceptual toolkit to understand how demand and supply activities are entangled in complex ways that necessitate holistic and multifaceted approaches to disentangle, balance, and analyze them in relation to one another. Accordingly, it would be a proper lens to examine the intriguing interplay between demand and supply.

Paradox is the dynamic tension of juxtaposed opposites and contradictions that emerge as part of actions and interactions. Paradox entails essentially inevitable manifestation of unintended and the often opposite corollary of actions such as collaboration (Gnyawali et al., 2016) or situations such as embeddedness (Putnam et al., 2016). Paradoxes "impose and reflect back on each other, and develop into seemingly irrational or absurd situations because their continuity creates situations in which options appear mutually exclusive, making choices among them difficult" (Putnam et al., 2016, p.72). Paradox stems from competing demands of the task and institutional environments or from organizational dynamics that induce politically guided behaviors such as power struggles (Astley \& Sachdeva, 1984; Corvellec \& Hultman, 2014). Paradoxical strategies are related to tensions between divergent approaches that are needed to be embraced as they are and delicately navigated to overcome (Smith et al., 2010). Thus, demand and supply paradoxes that subtly coexist and separately guide behaviors in different functions signify a critical behavioral puzzle.

Paradox theory has recently been applied to B2B marketing, especially concerning interorganizational coopetition (Gnyawali et al., 2016; Raza-Ullah, Bengtsson, \& Kock, 2014). However, the application of paradox to marketing literature expands to such issues as control and trust (Day et al., 2013; Huemer, Boström, \& Felzensztein, 2009) and the triple bottom line 
(Ozanne et al., 2016). This line of research in B2B marketing has sought to understand why contradictory yet interrelated elements exist simultaneously in marketing and what responses marketing managers adopt to handle such paradoxes. In this research, we use paradox theory as an approach that explains the persistent tensions at DSI.

Paradox often invokes inevitable yet worthwhile challenges for B2B marketing and marketing strategy: the complicated juxtaposition of opposites that are potentially rewarding once it is embraced and dexterously navigated. In fact, paradox does not inevitably connote negativity and can instead be navigated as a mechanism of change and innovation for better value creation. Adopting dual forms of organizing and structuring may even increase performance by fostering creativity and vigor if paradoxes they invoke are managed effectively and differences and tensions are channeled to creativity (Graetz \& Smith, 2008; Smith et al., 2010). In some instances, paradox can enable synergistic coexistence of multiple paradigms and leverage of productivity benefits, but this comes with unique challenges that require in-depth examination (Putnam et al., 2016).

Past frameworks exploring DSI and activities taking places at DSI has fallen short of capturing the reality and explaining the nature and role of demand and supply paradoxes. Little is known as to why the divide between demand and supply persists. Likewise, despite the breadth and depth of paradox theory, it has not been empirically applied to DSI. Drawing on the overview of the relevant literature and identified gaps, we seek to answer the following specific research questions: 1) What is the nature of demand and supply paradoxes? 2) How do B2B firms experience and handle demand and supply paradoxes? 3) How do managers' experiences and handling of demand and supply paradoxes influence the relationships between demand and supply activities?

\section{Research method}

\subsection{Research approach}

Demand and supply paradoxes are socially complex phenomena, inseparable from their organizational context, and are represented by scarce theoretical knowledge. Wilson (1998) suggests that qualitative research is most beneficial for the investigation of complexities and processes, little- 
known ways of management, and unstructured and informal linkages in firms. According to these criteria, qualitative research is a good fit for investigating demand and supply paradoxes. To this end, we adopt an exploratory, non-linear, qualitative research design to generate a theoretical framework that offers rich explanations and insights. This approach is consistent with work that examines complex issues (e.g., D'Antone et al., 2017). Our research involves data collected over two years in two stages (an initial one followed by the main one).

\subsection{Sampling and data collection}

The unit of analysis in this study is B2B firms' DSI. Our sample base consists of 19 firms, of which 5 are from the initial stage and 14 from the main stage, of different sizes operating in a variety of B2B industries located in Turkey to garner a wide range of experiences, perspectives, and narratives on the research issue in line with the theoretical sampling approach (Corbin \& Strauss, 2008). When selecting informants in each firm, we paid particular attention to interview those managers that have intimate and extensive knowledge pertinent our research inquiry. Likewise, Turkey represents a multifaceted social and business environment (Glaister et al., 2008), where different and paradoxical business paradigms, organizational cultures, and management systems dynamically coexist (Karakas, Sarigollu, \& Uygur, 2016). The unique blend of eastern and western business practices and innate organizational and managerial paradoxes bred by such blend in Turkey allowed us to gain richer insights into the study of demand and supply paradoxes.

The main source of data was face-to-face and semi-structured in-depth interviews with marketing and SCM executives or executives with marketing and SCM responsibilities. A total of 31 participants were interviewed over the course of two years. After the initial exploratory stage, we decided to continue with dyadic interviews whenever possible to capture complementary insights into demand and supply activities (Kenny, Kashy, \& Cook, 2006). Table 1 shows the characteristics of participants. The inclusion of different industries enabled us to make more meaningful cross-case analysis and find consistencies and differences among them (Eisenhardt, 1989). The similarities across participant firms included relationships between demand and supply activities, the existence 
of demand and supply paradoxes, and the subtle struggle between vital value-creating functions. These similarities allowed us to build our framework that was shared across participant firms.

\section{Insert Table 1 here}

The managers' responses to the common interview questions were largely consistent within each B2B firm that participated in the research with two respondents. This fostered the accuracy of findings through cross-informant validation. We sought to establish the balance between breadth and depth with the number of interviews to achieve right quantity and high quality of data. We continuously analyzed and constantly compared our evolving data within and across contexts to determine the extent of data collection. We continued collecting data until theoretical saturation, a stage at which no meaningfully new information arises (Gligor, Esmark, \& Golgeci, 2016), was reached. The size of our data also corresponds well to Creswell's (2007) suggestion of including 20 to 30 individuals to develop a well-saturated theory.

Interview questions included the issues of the participant firms' demand and supply activities and the nature and extent of relationships between them, the participant firms' organizational structure and functioning as well as interactions between marketing and SCM managers and employees, and challenges and paradoxes managers face when working with each other. We customized questions for marketing and SCM managers. Though we used the backbone of the standard protocol in interviews, we probed emergent issues further to gather deeper insights and establish a ground for triangulation as we proceeded with new interviews. We also allowed participants to steer the flow and content of discussion to minimize interviewer-induced bias. All interviews were discovery-oriented to enable research sensitivity, achieve a balance between structure and flexibility, and encourage candid and insightful inputs by participants (Wilkinson \& Young, 2004). Other data resources such as company reports, website resources, and on-site observations also provided interesting and complementary insights that triangulate findings. Utilizing multiple sources of evidence enhanced validity (Yin, 2009) by offering multiple measures and providing a holistic and contextual portrayal of the issues under investigation. 


\subsection{Analysis and trustworthiness}

The analytical approach involved "systematic combining" (Dubois \& Gadde, 2002). The core premise of this approach is the systematic combining of inductive and deductive approaches in seeking knowledge via a non-linear process of combining observations, empirical insights, and constantly consulting relevant literature (Dubois \& Gadde, 2002). This included loosely drawing on paradox theory without a deliberate attempt to form priori views about potential demand and supply paradoxes. In fact, we delved deeper into paradox theory only after discovering patterns in our data that could be better analyzed through paradox theory. Our discoveries during the initial stage led us to reshape our research focus in the main stage and embed paradox theory in our investigation and analysis. We juxtaposed the extant theory with the phenomenon we observed over the course of empirical research with data analyses ensuing the differences between the evidence and descriptions in the literature. This allowed the simultaneous and interactive evolvement of data and theory as well as the achievement of a relevant and rigorously validated framework for theory elaboration (Dubois \& Gadde, 2002; Piekkari, Plakoyiannaki, \& Welch, 2010).

Our data analysis started immediately following the first round of data collection and involved both within case analysis of each B2B firm and cross-case analysis of firms to reveal consistent patterns and differences (Eisenhardt, 1989). Data analysis consisted of a number of iterative steps (Corbin \& Strauss, 2008). First, based on a careful reading of interviews and firm documents, open coding (forming interim categories and first-order codes) was conducted. During this phase, pieces and aspects of the data were constantly compared to identify similarities and differences among them. We conducted further analysis with axial coding (integrating first-order codes and generating conceptual categories) and selective coding (bounding theory by combining theoretical dimensions) (Corbin \& Strauss, 2008). Eventually, the analysis of codes, memos, and resulting categories led to the emergence of the proposed framework.

We followed the recommendations by Lincoln and Guba (1985) and Marvasti and Silverman (2008) to maintain analytical rigor and establish the trustworthiness of the data. First, we employed 
Nvivo 10 software to assist the structuring and documentation in line with comprehensive data treatment. We thoroughly analyzed the data to enable the comparing and contrasting of responses and improve the interpretability based on firm and personal characteristics of participants. Then, we sought refutability by keenly looking for cases where our findings were inconsistent and suggestive of systematic differences. We noticed that most of our categories were transferable across firm sizes and industries (Lincoln \& Guba, 1985), though some differences existed about the nature of demand and supply activities. Furthermore, we followed a continuous, iterative process to combine the interviews findings with the extant theory on our research issue. In particular, we employed constant comparison to validate emergent themes and findings revealed in the interviews. We incorporated insights from preceding interviews into following ones until we reached theoretical saturation. We also used theoretical and diverse sampling; ensured that both the researchers and informants were active participants in the research process to support respondent validation; assured participants of anonymity; had key participants review the early reports of the research; and maintained professional and friendly interview climate to enhance trustworthiness.

\section{Findings and propositions}

In this section, we start with uncovering aspects of paradoxes that demand and supply activities engender. We then explore how facing, managing, and transcending demand and supply paradoxes shapes the interplay between demand and supply activities.

\subsection{The nature of demand and supply paradoxes}

The findings revealed that three distinct but interdependent patterns of demand and supply paradoxes that coexisted within participant firms. Based on the common thread that interweaves them, we call these paradoxes as demand and supply paradoxes. Drawing on our empirical findings and the existing literature on business paradoxes (e.g., Delbridge, 2007; Graetz \& Smith, 2008; Jarzabkowski, Lê, \& Van de Ven, 2013; Melnyk, Hanson, \& Calantone, 2010; Oliver, 2004; Tsai, 2002), we portray demand and supply paradoxes as simultaneous harmony and tension in the structures and relationships of firms' demand and supply activities. Demand and supply paradoxes 
are manifested through relationships between marketing and SCM managers and employees who have intensive interactions yet follow alternative approaches to value creation. Demand and supply paradoxes contain the gist of the three major paradoxes found between demand and supply activities: collaboration-competition, concord-conflict, and integration-differentiation. These three paradoxes embody the conundrum of following different means to the same end of value creation.

The coexistence of these three paradoxes appeared to have an important and dilemmatic influence on how employees behave and activities interact. Evidence quotes in Table 2 reveal that B2B firms had simultaneous and seemingly conflicting prescriptions guiding their way of doing business. These paradoxes were closely interlinked and appeared to oscillate (cf. Melnyk et al., 2010), drawing on the participants' retrospective accounts and future projections. In addition to quotes presented in Table 2, we depict the overview of data structure that demonstrates the means by which the aggregate theoretical dimension of demand and supply paradoxes emerge in Fig. 1.

\section{- Insert Table 2 here}

\section{Insert Fig. 1 here}

First, collaboration-competition paradox (i.e., coopetition) is defined as the simultaneous and dynamic coexistence of collaboration and competition across organizational functions (Tsai, 2002). This paradox indicates that collaborative behaviors contain a kernel competition and competitive behaviors contain a kernel collaboration both of which have potential to grow and create problems. Extant research reveals that collaboration-competition paradox is an important behavioral paradox experienced both within (Tsai, 2002) and across firm boundaries (Gnyawali et al., 2016; Raza-Ullah et al., 2014). This paradox suggests that collaboration and competition breed each other and cannot be fully understood regardless of the other. Though collaboration is a keystone of societal and economic progress, it is inextricably intertwined with competition (Harari, 2014).

We found that cross-functional collaboration was often highly pronounced in participant firms, but this did not prevent the existence of moderate or even high competition between marketing and SCM functions. On the one hand, collaboration was practiced due to top management push (as 
in SAuto) or cross-functional training and innate awareness of the benefits of intraorganizational collaboration (as in PFashion and Upbt). On the other hand, turf struggles between the functions created competition, which was strongly evident especially in TrdLrg and ElasPr.

Second, we also identified concord-conflict paradox, which refers to concurrent and varying levels of harmony and conflict among the employees of different functions (Delbridge, 2007). Concord-conflict paradox indicates that every concord contains a seed of potential or subtle conflict and every conflict maintains a kernel of concord. Conflict and concord is virtually unavoidable when the interaction between parties are intense and complex (Frazier, 1999). Accordingly, concord and conflict are not pure behavioral realities but are experienced within a spectrum of varying degrees of their co-existence that has to be managed simultaneously (Heikkila \& Weible, 2017). This behavioral paradox signifies the fragile state of concord people have with each other that could readily be jeopardized by subtle inherent conflicts as well as opportunities embedded in conflicts that can lead to fruitful outcomes.

Concord-conflict paradox was particularly exacerbated by Turkish business context that is characterized by diversity coupled with a relative lack of tolerance to it (Glaister et al., 2008). We also noted that marketing and SCM often were in concord with some aspects (e.g., the importance of value creation) while they were in conflict with others (e.g., means to create value) simultaneously. Organizational climate valuing diversity and openness to divergent values and practices was coupled with ensuing challenges and ambivalence. In the words of $\mathrm{H} 1$ from Crisp:

I have a hat that says I am responsible for SCM and operations, my brother taking care of marketing side. But, in reality, what we do is to do business and our roles are ambiguous.

We also found that social events that bring diverse functions and members together were effective practices to instill a culture of collegiality and harmony. For example, Upbt, PFashion, and BlogC organized leisure activities to promote cross-functional bonding.

Third, integration-differentiation paradox denotes seeking simultaneous achievement of separation of activities into distinct organizational functions via structural decoupling and 
modularity and of integration via coordination and unification (Terjesen, Patel, \& Sanders, 2012). Accordingly, this paradox is primarily of structural in nature and is a product of contemporary organizational design. Current business environment requires that economically high performing firms be both highly differentiated and well integrated (Lawrence \& Lorsch, 1967). Accordingly, while firms' functions differ in terms of formal subsystem structures as well as goal, time, and interpersonal orientations, they also seek integration between the subsystems (Lawrence \& Lorsch, 1967). The dual pursuit of integration and differentiation can be essential and inevitable reality of DSI within firms (Terjesen et al., 2012).

Integration-differentiation paradox resulted in concurrent interdependence and disconnection between marketing or SCM managers. Differentiation was practiced to prevent task ambiguity since some activities were not easily assigned to either marketing or SCM. Describing their whole business process, E1 from PFashion stated:

Our activities are highly intertwined and integrated. They follow a cyclical rather than a linear fashion. But, we still keep the functions separated. We believe this is needed to keep being focused. In fact, it was evident in the majority of the cases that marketing and SCM could not be fully coordinated due to different utilities of the functions or partial "frequency mismatch" as N2 from RvlAuto idiomatically put it. Nevertheless, one promising method to support coordination was the implementation of a dynamic and nimble tracking system that measures functions based on their contribution to high-priority customers and the sustainable value they create for the whole firm.

The gist of the finding on demand and supply paradoxes is that collaboration, concord, and integration did not exist in pure forms within B2B firms. They could not be purely experienced due to constant shifts and interactions caused by opposing forces. In other words, the forces that formed these states often contained the seeds of opposing forces which resulted in constant shifts and continuous balancing (Graetz \& Smith, 2008; Oliver, 2004). What IS2 from LightAce said exemplifies this notion:

Unfortunately, there is no one right solution or no ultimate destination. When you think you have arrived at the perfect solution, you face unforeseen side effects the next day. Then you try to tackle 
those side effects, which necessarily creates other complications. You are damned if you fix and damned if you don't. It is this messy patchwork that needs constant fixing, mending, and revamping.

We exemplify participant firms' experience in facing, managing, and transcending demand and supply paradoxes in Table 3 . We offer insightful cues on how demand and supply paradoxes shape demand and supply activities and what handling mechanisms firms follow. We elaborate on each theme below.

\section{Insert Table 3 here}

\subsection{Facing demand and supply paradoxes}

Our research revealed several patterns that illustrated the challenging dynamics of facing and appreciating demand and supply paradoxes. Several participants noted that some activities at DSI did not comply with each other, evoking paradoxes that initially engender ambivalence. For example, M1 from SAuto suggested:

We [SCM function] are pretty good at supplier selection and evaluation. ... We occasionally disqualify some suppliers producing parts that our customers require. At times, marketing ended up failing to serve customer requirements due to our supplier selectivity.

In their case, supplier selection practices by SCM created unsolvable paradoxes for customeroriented demand actives. Thus, we found that some managers at DSI felt ambivalence about their work, evaluating, and balancing competing expectations. For example, IS5 from Protech stated:

I find myself constantly working on opposite concerns. As an organization, we want to be both efficient and innovative. We want to use cutting-edge technology; but also tech-free solutions that require better reflection and interpersonal coordination. We want to satisfy our clients, but we also question or challenge them when necessary. Therefore, we constantly adjust and improvise.

Second, some managers explained how they felt stuck when they realized any decision they made would have contradictory outcomes and unintended consequences. For example, K1 from TrdLrg described handling power dynamics between marketing and SCM as a double-edged sword:

It is like walking on a rope. You must be delicate to protect the balance. Of course, there is politics and power dynamics between functions. As a top manager, I play thru tensions and conflicts to address these.

Likewise, some managers experienced cognitive dissonance in the face of tensions between demand and supply activities and goals. For example, $\mathrm{O} 2$ from ElasPr found the misalignment in key performance indicators (KPIs) puzzling and problematic: 
Currently, our KPIs are not aligned, and we see its negative implications for our performance and interfunctional collaboration. This is something that I have been contemplating and raised to our top management.

This complies with the literature on paradox where competing demands on core business processes provoke anxiety (Lüscher \& Lewis, 2008; Vince \& Broussine, 1996). Such anxiety can lead to defensive behaviors and spur vicious cycle that can hurt demand and supply (Smith \& Lewis, 2011).

Moreover, some participants described how they developed defensive mechanisms such as denial to avoid tensions. For example, both M2 from SAuto and R1 from NoDrnk recognized that while marketing and SCM were highly symbiotic, they tended to avoid facing cross-functional problems that were difficult to solve. Some participant managers explained how they tried to ignore or escape paradox (See Table 3); which resulted in cycles of oscillations. These patterns show that progress is by no means the only outcome of paradox, as the dark side can prevail and result in negative sequences of avoidance or ambivalence when managing their DSI that can erode potential synergies and amplify potential erosive interplay between demand and supply.

Proposition 1: B2B firms facing demand and supply paradoxes may experience ambivalence and avoidance when managing their DSI that can lead to weakening the reciprocal positive influences and strengthening reciprocal negative influences between demand and supply activities.

\subsection{Managing demand and supply paradoxes}

Participants noted that the relationships between demand and supply activities could be both synergistic and erosive. For example, S1 from $U p b t$ argued the following:

Our marketing function's capacity in market intelligence helps the SCM to be more responsive and nimble thanks to increased supply chain visibility.

Demand activities of market intelligence gathering learning played a positive role in enhancing supply chain visibility by accessing the knowledge channels of supply chain partners. However, T1 from SVision exemplified how some supply activities could indeed hamper demand activities:

We have diligent and time-consuming quality assuring supply management processes. As a result, marketing cannot always find opportunities to meet some customer requirements. 
Some demand activities of SVision was curtailed due to supply restrictions and slowdowns imposed by conscientious supply management processes. These two exemplary quotes illustrate how the interplay between demand and supply activities could be both synergistic and erosive.

Our research further revealed how the participant firms managed the three major demand and supply paradoxes in relation to DSI. First, amplifying the deviation between collaborationcompetition created targeting and activity dissonances. For example, P1 stated:

Sometimes, we experience disconnections and problems during our cross-functional collaboration for such processes. ... Still, we are able to cover each other's weaknesses and support each other. When high collaboration was coupled with high competition, we noted that activity relationships became unproductive. For example, K1 from TrdLrg linked performance deficiencies of their demand activities to organizational power struggles during internal competition for influence on firm strategy and marketing being repeatedly bashed by SCM. Power asymmetry between the functions obstructed their interactions and left potential synergies inert. O1 from ElasPr stated:

When people from different functions compete, things get more complicated, because then you cannot be sure whether the other party has a hidden agenda.

High competition in the presence of intensive collaboration appeared to weaken the alignment of key performance indicators and activity synchronization in several B2B firms. In contrast, when collaboration met milder competition that balanced the inherent paradox (as in SVision, Upbt, and Crisp), activity synergies appeared to be stronger and more fruitful. Activity complexity was reduced. For example, M2 from SAuto stated:

We [marketing function] indirectly benefit from our firm's suppliers located in the target market to gather and use information not only on the market and potential customer but also on technologies.

This statement hints that relational supply activities offer unique benefits to learning activities of marketing function especially when marketing and SCM alleviate collaboration-competition paradox when serving the firm's customers. This finding on balancing collaboration-competition paradox is also in line with recent research that milder competition can spur cross-functional knowledge sharing (Nguyen et al., 2017). 
When it comes to concord-conflict paradox, firms that reported stronger concord than conflict between the functions often declared positive and synergistic relationships among their activities. For example, P1 stated:

I am aware that we need to look after each other [marketing and SCM functions], but when we are not on the same page regarding our shared business activities, then we hinder each other.

It was a statement of awareness of the need for high concord for smooth and effective synergies between demand and supply activities. Nonetheless, amplified paradox evoked organizational dissonance that had negative implications for activity relationships. In the words of $\mathrm{O} 2$ from ElasPr:

We [marketing function] cannot really utilize the capabilities of the SCM, because our goals and activities are not aligned.

Thus, we realized that amplifying the tensions between concord and conflict dimensions of intraorganizational relationships resulted in impeding influences on activity synergies.

Referring to integration-differentiation paradox, some participants such as $\mathrm{N} 2$ from RvlAuto and C2 from SeaCom stated that integration was necessary to increase mutual awareness for better leverage of different activities in tandem. However, other participants suggested that uneven integration led to counterproductive work behaviors like emoting, role conflict, or freeriding, and some differentiation was needed to avoid confusion and foster accountability. For example, both N2 from RvlAuto and T2 from SVision complained about unrealistic expectations of their marketing from SCM due to the high differentiation of some of their activities. Similarly, participants from some larger B2B firms contended that complex processes and structures linked with structural differentiation obscured activity synergies. For example, P1 stated:

I can see that our market expansion ability often curbs distribution capability and reliability of the SCM function. Managing the high complexity of operations in several countries became daunting. We face the danger of losing connection with some of our key customers due to the difficulty of effective integration.

Further, A2 from $B \log C$ linked structural differentiation and resulting disconnect between demand and supply activities to power asymmetries. Higher differentiation over integration hindered activity 
synergy due to intraorganizational obliviousness and power asymmetries. Balancing integrationdifferentiation paradox gave rise to better activity synergies (see Table 3).

Proposition 2: Amplifying (balancing) demand and supply paradoxes weakens (strengthens) the reciprocal positive influences and strengthens (weakens) reciprocal negative influences between demand and supply activities.

\subsection{Transcending demand and supply paradoxes}

The interviews also revealed some common themes in what mechanisms were used to reframe and transcend demand and supply paradoxes. There were implicit ideas in the participants' minds regarding paradoxes arising from the tensions between demand and supply sides of their firms. For some managers, demand and supply paradoxes were intrinsically related to high stake decisions or continued dilemmas. For others, they reflected deep conflict and subsequent rounds of struggles and negotiations. Yet for others, these paradoxes seemed to be linked with complexity and ambiguity of processes and expectations at work. Hence, managers developed a number of mechanisms to handle demand and supply paradoxes, and some reframed them to synthesize a new whole. Subsequent analysis surfaced different yet interrelated forms of paradox-handling mechanisms for better demand and supply management (See Fig. 2).

\subsubsection{Reflective practices and integrative decision-making}

We found that managers who were engaged in mindful and reflective practices and reframed alternative approaches into a more unified one achieved better demand and supply integration. Their sensemaking of managerial tasks led to greater cognitive and behavioral erudition and mutual understanding for integrative and nuanced decisions. We found this solution to be related to all three types of demand and supply paradoxes, as mindful practices and integrative decision-making are holistic in nature and can be applied to both behavioral and structural elements of demand and supply paradoxes. In view of this, L1 stated:

Following a deliberate strategy and process, we adopted a product-based view of our firm. For example, working six years as a procurement director and having worked four years on the marketing 
side, in reality, I almost do the same job. It revolves around steel rather than a function I work at.

This allows me to appreciate market and product realities better and eliminate potential dilemmas between marketing and SCM.

Managers in SarSt reflected more on market and product realities when they are making decisions concerning organizational structure and interacting with each other at DSI and tackle paradox rather than being confined to a functionalist and narrow view of marketing and SCM. This often led to more systematic knowledge sharing behaviors across the firm's functions and better organization of marketing and SCM processes. The transformative role of reflective practices and integrative decision-making could be seen both in employee behaviors and organizational structure such that managers with higher reflective practices and unifying decisions were better able to understand, accept, and rise above everyday paradoxes faced at DSI. Hence, reflective practices were considered a means for transcending demand and supply paradoxes and achieving greater synergy.

\subsubsection{Cross-functional consultation and coordination meetings}

Some managers within our sample led firm-wide initiatives to bridge gaps and promote multistakeholder coordination and learning in their firms as another means of transcending demand and supply paradoxes. These initiatives often involved cross-functional consultations and ad-hoc coordination meetings. The crux of these initiatives was to overcome the vicious cycle of covert conflicts hidden within overt concord stemming from not only competing priorities but also the lack of awareness and understanding. Communication and managers' accompanying ability to talk and listen were seen as a fundamental remedy to such challenges.

In cross-functional consultations and ad-hoc coordination meetings, there was often a dual focus on understanding forecasting demand and customer service issues, as well as supply chain and inventory issues. From a sales perspective, demand considerations such as whether the firm needs to stimulate demand to meet sales goals were reviewed. From an operations perspective, supply issues such as the question of excess inventory and supply chain costs were considered. These meetings also considered seasonal fluctuations, industry forecasts, economic indicators, market dynamics, and momentary changes to prepare for contingencies. In particular, these meetings 
worked better for concord-conflict type of paradox where conflicts were channeled toward productive outcomes and different functions negotiated the terms of a solution that worked for both parties. The primary goal of these activities was to reconcile futile conflicts stemming from alternative approaches without letting one function to dominate the other. For instance, O1 stated:

The best solutions are not necessarily bland halfway points between the extremes. Instead of compromising, you need to be creative, resourceful, and try to find a third way. We recently started a cross-functional project to accelerate firm-wide innovation and customer service. Of course, we face resistance, but the team implementing this initiative is achieving results and earning its legitimacy. Through this initiative, we hope to achieve a more creative and dynamic unity across our functions. We started giving rewards to our employees who come up with best ideas and best practices. For example, one of our IT guys suggested the use of integrated project management software that can track progress of multiple teams and departments. It was really cool and got positive feedback from different departments.

This statement follows a similar logic to cross-functional communication initiatives by A2 from $B \log C$ that faces a plurality of stakeholders and goals (Table 3). At the heart of these initiatives were principles of joint business planning; prioritizing resources around key customers; conducting shared strategy meetings, and balancing supply chain capacity with new opportunities or demands. In cases of argumentation or jurisdictional struggles between marketing and SCM functions, crossfunctional consultations and meetings proved instrumental in how diverse players managed, interpreted, and transformed the relationships between contradictory elements. Thus, crossfunctional initiatives indeed helped resolve demand and supply paradoxes, especially those related to concord-conflict.

\subsubsection{Innovative organizing for integral solutions}

Some participants described how they exhibited creativity for innovative organizing to develop integral solutions linking functional boundaries and activities. To achieve dynamic synthesis across functions, these managers envisioned and implemented third-way solutions. In particular, these solutions worked better for integration-differentiation paradox where organizational stakeholders sought to achieve flexible structures that combine decoupling and integration with limited their collateral complications. For example, H1 stated: 
Only through accepting the ambiguities and contradictions can we come up integral solutions that move us forward. These solutions require imagination and synthesis of diverse forms of knowledge. Once we developed the intellectual muscles and resilience to acknowledge paradox as a natural condition of our work, we have been able to design good solutions that transcend dualities. When you stop thinking in dichotomies, a whole new space opens up in your brain... It is refreshing and exciting actually... You can imagine and create flexible ways of organizing... You go beyond the existing frames of reference to find common ground that can hold the interests of all parties.

This fresh and open approach enabled the firm to hear ideas from diverse employees; which, in turn, resulted in handy structural innovations. Moreover, some firms implemented integrated business planning systems involving people, process, and technology elements of the business to bridge gaps among functions. One note-worthy technological innovation mentioned was cloud technology that connected sales and operations planning processes with higher-level strategies. On the other end, another firm initiated a cross-functional team empowered to initiate a training system aimed at encouraging firm-wide collaboration. Another firm initiated a joint demand and supply planning system that based inventory allocations on real-time demand forecasts incorporating data from all parties and teams (operations, inventory, sales, and promotions). Finally, a family business assigned an executive team to bridge gaps in relevant functions.

What was common to these initiatives was the shared goal to achieve a seamless and synchronized collaboration process that connected data points and information all the way from suppliers to customers. It took a particular quality of innovative leadership to cross boundaries, resolve conflicts, and transcend paradox through innovative organizing. It required both internal and external collaboration as well as a willingness to share both information and risk. These organizations found new ways of organizing and structuring multifaceted relationships through an inspiring expansive vision. This vision provided a framework for imagining and discovering new areas of convergence across conventional differences.

\subsubsection{Coping with ambiguity through improvisation and iteration}

Participants pointed out to the unique mindset and resilience that managers developed while operating in the sociocultural and business context of Turkey, characterized by a high level of 
uncertainty, confusion, and non-linear change that cultivate paradox. It could be argued that improvisational skills -such as navigating stormy waters, handling systemic uncertainty, momentary sense-making, and iterating- often proved to be immensely valuable in resolving paradox. These skills helped in building responsive agility - managers could then deploy dynamic planning capabilities, shifted plans and fine-tuned operations, rapidly responded to market or demand changes, and minimized shocks. In particular, responsive agility worked better for collaborationcompetition paradox where diverse organizational players sought to improvise their strategies through coopetitive and adaptive behaviors. Improvisation was seen particularly handy when the managers lacked necessary tangible and intangible resources to face paradoxical challenges at DSI.

In the inherent ambiguity of Turkish daily life that embodies competing with collaborators and collaborating with competitors, participants explained how contradictions and paradoxes lie at the heart of everyday organizing and finding integral solutions. IS1 from Icecom underlined this competence as follows:

It is never easy to conduct business in Turkey's socioeconomic landscape. It is an endless struggle. It is our job to handle chaos. We do whatever it takes to resolve or navigate or ease these challenges. Sometimes we improvise; sometimes we compromise. However, we are always prepared for unforeseen circumstances. You have to expect the unexpected to survive in the valley of the wolves. I think this is why Turkish managers know how to handle crisis or entanglement. Each of our friends (managers) working here knows and prepares for these contingencies. Each one of us is incredibly resourceful, resilient, and flexible.

In short, improvisation and iteration were necessary to steer simultaneously collaborative and competitive organizational landscape and cope with the ambiguity of sophisticated dynamics of coopetition between marketing and SCM functions in Icecom and some of the other firms in our sample.

Proposition 3: B2B firms that reframe and transcend demand and supply paradoxes achieve greater synergy between demand and supply activities.

Our exploration of the nature of tensions that feed demand and supply paradoxes, the evolution of demand and supply paradoxes as managers experience, manage, and transcend them, and 
propositions on their influence on the relationship between demand and supply accumulate to the dynamic model shown in Fig. 2. Thus, our model provides an account of research questions we asked and can be used for further exploration of demand and supply paradoxes.

\section{Insert Fig. 2 here}

\section{Discussion and implications}

\subsection{Theoretical contributions}

The essence of this study lies in its attempt to clarify the underlying dynamics of the relationships between firms' key demand and supply activities through paradox theory. We explore demand and supply activities and thus respond to calls for research that examines the complexities of the demandsupply interface (DSI) (Santos \& D'Antone, 2014). This research is a rare example of probing into the interplay between demand and supply as key business processes and possibly the only one that also accounts for the role of the intuitive yet ignored concept of paradox at DSI. Our study explains why only a small minority of firms adopt integrative approaches to demand and supply, despite its assumed advantages. Thus, insights from this study contribute to bridging the gap between theory and practice at DSI.

We have identified three categories of demand and supply paradoxes, namely collaborationcompetition, concord-conflict, and integration-differentiation. Results demonstrate how these paradoxes are experienced simultaneously in the B2B firms we studied. Our findings on these paradoxes cement and fuse the fragmented evidence that collaboration, concord, and integration do not typically exist in pure forms but are influenced by their counterparts (Delbridge, 2007; Lawrence \& Lorsch, 1967; Tsai, 2002). Two important competing logics drive demand and supply paradoxes in B2B firms: the demand logic of market differentiation and expansion vs. the supply logic of standardization and efficiency. Unlike purist theories that often study cross-functional interactions unidimensionally and in a formulaic way, our findings on demand and supply paradoxes provide a fuller picture of demand and supply phenomena vis-à-vis organizational structure and design by 
capturing the nature of paradoxical patterns (Oliver, 2004; Smith et al., 2010). Paradox is an inherent part of a B2B firm, and it can fashion synergies and capacities just as it can spark challenges.

Although this study focuses on how marketing and SCM interact for creating value; the implications of these findings go beyond the functional orientations. The competing approaches of demand and supply permeate firms and their business models since they often reflect the two sides of any firm -the 'demand' side (the opportunities and market interactions leading to demand creation and ultimately revenues), and the 'supply' side (demand fulfillment achieved through production processes, activities, and resources that become the firm's cost structure). Our research has illustrated how managers deal with the dynamics between these two sides. We extend the research on paradox by focusing on the ways that seemingly unnecessary, but pervasive demand and supply paradoxes are central to marketing and organizational design. We highlight that amplifying the deviation in such paradoxes weaken synergy between demand and supply activities in the pursuit of creating relevant value. Amplifying paradoxes can create hurdles such as cognitive and behavioral dissonance, power asymmetries, and obliviousness. They, in turn, hamper potential adoption and innovative execution of effective strategies for the management of business processes at DSI. Our research is helpful in exploring how these paradoxes are enacted in the ways the firm's key functions interact and communicate with one another and why bridging demand and supply through recently developed frameworks focusing on demand and supply integration is not as categorical as it seems to be (cf. Esper et al., 2010; Jüttner et al., 2007).

Our research has illustrated how managers strategize and deal with the dynamics of DSI. In particular, we find that balancing demand and supply paradoxes strengthens the reciprocal positive influences and weakens reciprocal negative influences between demand and supply activities. Likewise, we find that firms that reframe and transcend demand and supply paradoxes through reflective practices, communication and coordination, innovative organizing, improvisation and iteration achieve greater synergy between demand and supply activities. We articulate that while reflective practices are related to all three demand and supply paradoxes; communication and 
coordination are primarily related to concord-conflict, innovative organizing is primarily related to integration-separation, and improvisation and iteration are primarily related to collaborationcompetition. These findings create a window into the specific ways that B2B firms pursue both sides of the demand and supply equation. By highlighting the importance of paradoxes woven into manager's mindsets, we point out how managers can construct imagined possibilities that reframe and transcend demand and supply paradoxes. Our findings suggest how some B2B firms and managers accept paradox and diligently reflect on its implications; which in turn unleashes a new mindset, creative energy, and behavioral complexity for transcending paradoxes and fostering synergy between demand and supply activities.

\subsection{Managerial implications}

Our research speaks to managers who are puzzled by the paradox they face when coordinating their demand and supply activities toward a seemingly straightforward and overarching goal of value creation. First, we show that B2B firms can face paradox when managing demand and supply, given the divergent nature of such business processes and alternative approaches that undergird them. Thus, managers are advised to make sense of and manage paradoxes through tolerating, embracing, balancing, and harmonizing alternative approaches. They should monitor and mitigate forces that exacerbate the dark side of paradoxes and alleviate dissonance, power struggles, and insensitivity. Reaping the benefits of potential synergies between demand and supply activities requires inclusive and fluid organizational design as well as recognition and judicious management of demand and supply paradoxes that managers live with.

Moreover, managers might benefit from learning about and analyzing diverse forms of managing paradoxes and developing proper means toward leading change for superior value creation. Appreciating paradoxes may enable managers to examine organizational goals through contrasting lenses, triangulate the different views, and arrive at a synthesis that recognizes the validity of each view and its integration with others. Managers who are entrenched in one view could limit themselves to their conceptual repertoire and miss the bigger picture when designing and 
executing their strategy. Instead, by recognizing that there is a meaningful array of forms of experience, managers can welcome multiple perspectives and visions for successful demand and supply management. Executing and achieving third-way solutions that go beyond sub-optimal agendas demand combining overarching visions and agenda-specific goals, shared incentives, synchronization, willingness to learn and experiment, engaging conflict, and finally unwavering perseverance (cf. Esper et al., 2010; Smith et al., 2010; Tate et al., 2015).

The range of demand and supply paradoxes explored in this study enables us to examine contradictions through multiple lenses and arrive at a holistic picture of managing DSI. Thus, encouraging managers to extend their vision by embracing alternative views seems a promising means for creating a well-rounded and balanced view. Using this research, managers can develop a more profound understanding of paradoxes inherent in demand and supply activities as well as demand and supply approaches. They can discover the multiplicity of goals and expand their dictionary on paradox to envision and lead effective change.

Findings demonstrated four ways of transcending paradoxes: reflective practices and integrative decision-making; cross-functional consultation and coordination; innovative organizing for integral solutions; and coping with ambiguity through improvisation and iteration. These emergent solutions imply that practitioners need to go beyond the partial perspective they see through their own positions, juxtapose contradictory elements of supply and demand considerations, and follow dynamic decision-making. It purports that a holistic consideration of these considerations provides practitioners the big picture and guidance on how to simultaneously attend to competing demands of demand and supply and transcend this paradox. The findings indicate the importance of a dialectic process of resolving contradictory elements embedded in DSI through iterating responses of dividing and integrating demand and supply activities as prerequisites for transcending supply and demand paradoxes.

\subsection{Future research}


Future research can build on this study to explore the subject further. First, an in-depth examination of why demand and supply paradoxes exist within a firm or function may create an interesting research avenue. Second, demand and supply paradoxes can influence and be shaped by organizational environment. Major processes at DSI can be linked to various factors such as primary self-identification domains of employees, as their identity shape their logics and priorities. Likewise, an organic organizational climate fostering unity in diversity and cohesiveness can render different cycles of demand and supply paradoxes than a contentious organizational climate fostering individual competitiveness and inertia. The role of top managers with an overarching vision of the firm and its demand and supply activities coupled with potential disconnect with middle managers can also reveal interesting insights. Exploring different antecedents and boundary conditions of demand and supply paradoxes within their organizational context could offer further insights into how to respond them more effectively and create a virtuous cycle of value creation.

Third, studying the role of various types, dimensions, and dynamics of paradoxes in other B2B marketing strategy phenomena can be a valuable pursuit. Though management research has made great strides in paradox research (Schad et al., 2016), B2B marketing and marketing strategy are lagging behind in theorization, and this offers a strong niche for theorizing within the fields of B2B marketing and marketing strategy. Fourth, our findings offered initial insights into how the local cultural context shapes managers' cognitive and behavioral patterns and ensuing experiences of and responses to paradoxical demands in their daily lives. Further research in different cultural contexts could further illustrate the nuances of these cultural dynamics and how they shape managers' perceptions and experiences of coping with paradoxes in organizational life.

Furthermore, an essential next step in this line of research would be to create a practical toolkit and guide that helps practitioners assess and combine their perspectives with respect to supply and demand considerations. In cases of potential conflict between different functions, it is essential to provide customized guidance and mentoring for practitioners to help them overcome the dominance 
of one perspective at the expense of the other. The inventory can include practical recommendations for practitioners to find a balance and create effective responses to demand and supply paradoxes.

Demand and supply paradoxes do not emerge in a vacuum. They emerge in relation to diverse business orientations, corresponding sub-cultures, and necessities. Paradoxes comprise many elements of a nexus that create clashing forms of orientations and identities. Participants' perceptions of paradoxes are situated and contextualized within the nexus of these relationships, discourses, and influences. Further research on paradox can benefit from holistic perspectives that capture how managers make sense of and handle these diverse paradoxes.

\subsection{Conclusion}

Paradoxes are an indispensable element of firms, yet they remain elusive and theoretically underdeveloped in the realm of demand and supply. The findings have contributed to the expanding literature on how firms manage demand and supply paradoxes. We aimed to develop a generative understanding of how managers manage demand and supply paradoxes. In doing so, we underlined the creative capacity of managers in envisioning and executing third-way solutions. Through paradox lens, we call for a more dynamic, holistic, and fluid way of understanding demand and supply in firms. Transcending paradoxes evokes managers to imagine new possibilities for matching demand and supply and envision new ways of doing business. This paper has underlined the significance of appreciating and embracing paradox in envisioning, initiating, and executing spaces of possibility and change. In this respect, transcending paradoxes embodies the managerial capacity for holistic change, learning, and innovation; as well as the determination to resist sub-optimal and fragmented solutions for demand and supply management. 


\section{References}

Astley, W. G., \& Sachdeva, P. S. (1984). Structural sources of intraorganizational: Power: A theoretical synthesis. Academy of Management Review, 9(1), 104-113.

Chatain, O. (2011). Value creation, competition, and performance in buyer-supplier relationships. Strategic Management Journal, 32(1), 76-102.

Corbin, J. M., \& Strauss, A. L. (2008). Basics of qualitative research: Techniques and procedures for developing grounded theory. Los Angeles, CA: Sage Publications, Inc.

Corvellec, H., \& Hultman, J. (2014). Managing the politics of value propositions. Marketing Theory, 14(4), 355-375.

Creswell, J. W. (2007). Qualitative inquiry \& research design: Choosing among five approaches: Sage Publications, Inc.

D'Antone, S., Canning, L., Franklin-Johnson, E., \& Spencer, R. (2017). Concerned innovation: The ebb and flow between market and society. Industrial Marketing Management.

Day, M., Fawcett, S. E., Fawcett, A. M., \& Magnan, G. M. (2013). Trust and relational embeddedness: Exploring a paradox of trust pattern development in key supplier relationships. Industrial Marketing Management, 42(2), 152-165.

Delbridge, R. (2007). Explaining conflicted collaboration: A critical realist approach to hegemony. Organization Studies, 28(9), 1347-1357.

Drucker, P. F. (1973). Management. New York, NY: Harper \& Row.

Dubois, A., \& Gadde, L. (2002). Systematic combining: An abductive approach to case research. Journal of Business Research, 55(7), 553-560.

Eisenhardt, K. M. (1989). Building theories from case study research. Academy of Management Review, 14(4), 532-550.

Esper, T. L., Ellinger, A. E., Stank, T. P., Flint, D. J., \& Moon, M. (2010). Demand and supply integration: A conceptual framework of value creation through knowledge management. Journal of the Academy of Marketing Science, 38(1), 5-18.

Frazier, G. L. (1999). Organizing and managing channels of distribution. Journal of the Academy of Marketing Science, 27(2), 226-240.

Fugate, B. S., Mentzer, J. T., \& Stank, T. P. (2010). Logistics performance: Efficiency, effectiveness, and differentiation. Journal of Business Logistics, 31(1), 43-62.

Glaister, K. W., Dincer, O., Tatoglu, E., Demirbag, M., \& Zaim, S. (2008). A causal analysis of formal strategic planning and firm performance: Evidence from an emerging country. Management Decision, 46(3), 365-391.

Gligor, D. M., Esmark, C. L., \& Golgeci, I. (2016). Building international business theory: A grounded theory approach. Journal of International Business Studies, 47(1), 93-111.

Gnyawali, D. R., Madhavan, R., He, J., \& Bengtsson, M. (2016). The competition-cooperation paradox in inter-firm relationships: A conceptual framework. Industrial Marketing Management, 53, 7-18.

Graetz, F., \& Smith, A. C. (2008). The role of dualities in arbitrating continuity and change in forms of organizing. International Journal of Management Reviews, 10(3), 265-280.

Harari, Y. N. (2014). Sapiens: A brief history of humankind. London, UK: Harvill Secker.

Heikkila, T., \& Weible, C. M. (2017). Unpacking the intensity of policy conflict: A study of Colorado's oil and gas subsystem. Policy Sciences, 50(2), 179-193.

Huemer, L., Boström, G.-O., \& Felzensztein, C. (2009). Control-trust interplays and the influence paradox: A comparative study of MNC-subsidiary relationships. Industrial Marketing Management, $38(5), 520-528$.

Hung, H.-M. (2010). Reconciling the paradox of supply-side and demand-side strategies in industrial innovation. Industrial Marketing Management, 39(2), 342-350.

Jarzabkowski, P., Lê, J., \& Van de Ven, A. H. (2013). Responding to competing strategic demands: How organizing, belonging, and performing paradoxes coevolve. Strategic Organization, 11(3), 245-280.

Jüttner, U., Christopher, M., \& Baker, S. (2007). Demand chain management-integrating marketing and supply chain management. Industrial Marketing Management, 36(3), 377-392.

Jüttner, U., Christopher, M., \& Godsell, J. (2010). A strategic framework for integrating marketing and supply chain strategies. International Journal of Logistics Management, 21(1), 104-126. 
Karakas, F., Sarigollu, E., \& Uygur, S. (2016). Exploring the diversity of virtues through the lens of moral imagination: A qualitative inquiry into organizational virtues in the Turkish context. Journal of Business Ethics, 1-14.

Kenny, D. A., Kashy, D., \& Cook, W. L. (2006). Dyadic data analysis. New York, NY: Guilford Press.

Lawrence, P. R., \& Lorsch, J. W. (1967). Differentiation and integration in complex organizations. Administrative Science Quarterly, 1-47.

Lincoln, Y. S., \& Guba, E. G. (1985). Naturalistic inquiry. Newbury Park: Sage Publications.

Lüscher, L. S., \& Lewis, M. W. (2008). Organizational change and managerial sensemaking: Working through paradox. Academy of Management Journal, 51(2), 221-240.

Malshe, A., Johnson, J. S., \& Viio, P. (2017). Understanding the sales-marketing interface dysfunction experience in business-to-business firms: A matter of perspective. Industrial Marketing Management, 63, 145-157.

Marvasti, A., \& Silverman, D. (2008). Doing qualitative research: A comprehensive guide. Thousand Oaks, CA: Sage Publications.

Melnyk, S. A., Hanson, J. D., \& Calantone, R. J. (2010). Hitting the target...but missing the point: Resolving the paradox of strategic transition. Long Range Planning, 43(4), 555-574.

Mentzer, J. T., Stank, T., \& Esper, T. (2008). Supply chain management and its relationship to logistics, marketing, production, and operations management. Journal of Business Logistics, 29(1), 31-46.

Nguyen, N. P., Ngo, L. V., Bucic, T., \& Phong, N. D. (2017). Cross-functional knowledge sharing, coordination and firm performance: The role of cross-functional competition. Industrial Marketing Management.

Oliver, A. L. (2004). On the duality of competition and collaboration: Network-based knowledge relations in the biotechnology industry. Scandinavian Journal of Management, 20(1), 151-171.

Ozanne, L., Phipps, M., Weaver, T., Carrington, M., Luchs, M., Catlin, J., . . Williams, J. (2016). Managing the tensions at the intersection of the triple bottom line: A paradox theory approach to sustainability management. Journal of Public Policy \& Marketing, 35(2), 249-261.

Paquin, R. L., Busch, T., \& Tilleman, S. G. (2015). Creating economic and environmental value through industrial symbiosis. Long Range Planning, 48(2), 95-107.

Piekkari, R., Plakoyiannaki, E., \& Welch, C. (2010). 'Good'case research in industrial marketing: Insights from research practice. Industrial Marketing Management, 39(1), 109-117.

Putnam, L. L., Fairhurst, G. T., \& Banghart, S. (2016). Contradictions, dialectics, and paradoxes in organizations: A constitutive approach. The Academy of Management Annals, 10(1), 65-171.

Raza-Ullah, T., Bengtsson, M., \& Kock, S. (2014). The coopetition paradox and tension in coopetition at multiple levels. Industrial Marketing Management, 43(2), 189-198.

Santos, J. B., \& D'Antone, S. (2014). Reinventing the wheel? A critical view of demand-chain management. Industrial Marketing Management, 43(6), 1012-1025.

Schad, J., Lewis, M. W., Raisch, S., \& Smith, W. K. (2016). Paradox research in management science: Looking back to move forward. The Academy of Management Annals, 10(1), 5-64.

Smith, W. K., Binns, A., \& Tushman, M. L. (2010). Complex business models: Managing strategic paradoxes simultaneously. Long Range Planning, 43(2-3), 448-461.

Smith, W. K., \& Lewis, M. W. (2011). Toward a theory of paradox: A dynamic equilibrium model of organizing. Academy of Management Review, 36(2), 381-403.

Tate, W. L., Mollenkopf, D., Stank, T., \& da Silva, A. L. (2015). Integrating supply and demand. Sloan Management Review, 56(4), 16-18.

Terjesen, S., Patel, P. C., \& Sanders, N. R. (2012). Managing differentiation-integration duality in supply chain integration*. Decision Sciences, 43(2), 303-339.

Tsai, W. (2002). Social structure of "coopetition" within a multiunit organization: Coordination, competition, and intraorganizational knowledge sharing. Organization Science, 13(2), 179-190.

Vince, R., \& Broussine, M. (1996). Paradox, defense and attachment: Accessing and working with emotions and relations underlying organizational change. Organization Studies, 17(1), 1-21.

Wilkinson, I., \& Young, L. (2004). Improvisation and adaptation in international business research interviews. In R. Marschan-Piekkari \& C. Welch (Eds.), Handbook of qualitative research methods for international business (pp. 207-223). Cheltenham, UK: Edward Elgar Pub.

Wilson, V. A. (1998). Qualitative research: An introduction. Purposes, methodology, criteria for judgment, and a rationale for mixed methodology. 
Yin, R. K. (2009). Case study research: Design and methods (4th ed.). London, UK: Sage Publications, Incorporated. 


\section{First-Order Codes}

- Statements about "cross-functional coordination"

Referrals to changing "power dynamics" across marketing and SCM functions

- Statements about "subtle competition" being embedded in collaborative processes

- Statements about "distance between managers" during collaborative activities due to "power struggle" among functions

- Statements about "harmony" in activities across functions tied with "discord" in priorities

- Referrals to "sharing same language" across functions

- Referrals to conflicts due to "deviant interests" and "contradicting goals"

- Statements about "common understanding" and "cross-functional awareness" along with complaints about "corresponding managers' insensitivity" to the realities of the focal function

- Referrals to "integrative approaches" followed by marketing and SCM managers

Statements about "complex processes" and their disconnecting implications

- Referrals to periodic changes in the intensity of "cross-functional communication"

- Referrals to "direct and indirect" means of communication and their oscillating dynamics

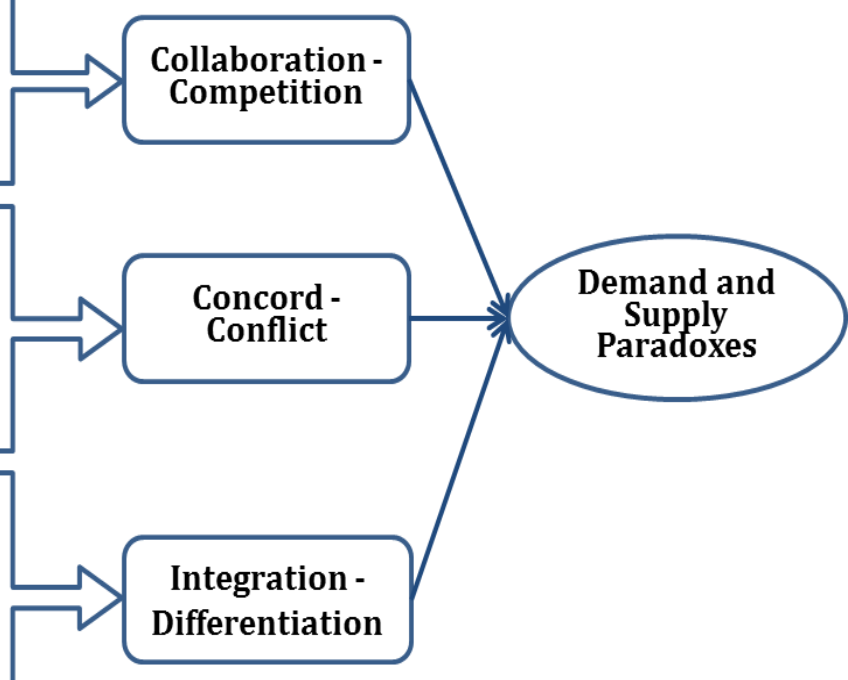

Fig. 1. Overview of data structure for demand and supply paradoxes

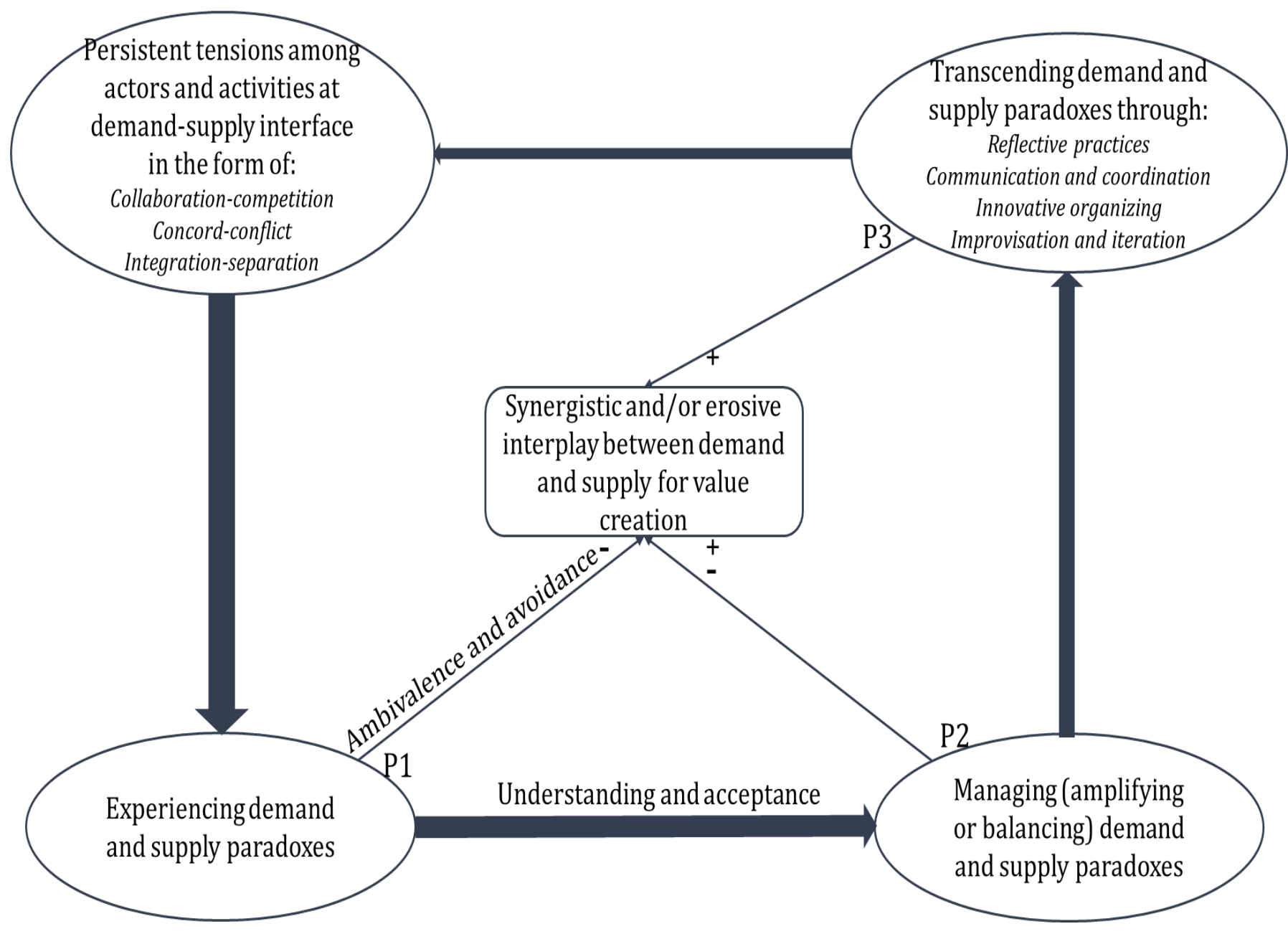

Fig. 2. A model of demand and supply paradoxes and their influence 
Table 1. The characteristics of participant firms and positions of interviewees

\begin{tabular}{|c|c|c|c|c|}
\hline Firm & Industry & Firm size & Participation stage & Participant pseudonym and position \\
\hline Icecom & Food \& Beverage & Medium & Initial & IS1-Vice President \\
\hline LightAce & Clothing \& Retailing & Small & Initial & IS2- Marketing Manager \\
\hline VStyle & Clothing \& Retailing & Medium & Initial & IS3- Associate Director \\
\hline$B s c F d$ & Food \& Beverage & Large & Initial & IS4- SCM Department Head \\
\hline ProTech & Electronics & Small & Initial & IS5- Partner \\
\hline$B \log C$ & Logistics & Large & Main & $\begin{array}{l}\text { A1-Operations Development Specialist } \\
\text { A2-Distribution Sales Director }\end{array}$ \\
\hline CountCc & Chemicals & Medium & Main & $\begin{array}{l}\text { Z1-Marketing Director } \\
\text { Z2-Procurement Manager }\end{array}$ \\
\hline SeaCom & Chemicals & Medium & Main & $\begin{array}{l}\text { C1-Logistics Director } \\
\text { C2-Sales Operations Manager }\end{array}$ \\
\hline SVision & Electronics & Small & Main & $\begin{array}{l}\text { T1-Marketing Director } \\
\text { T2-SCM/Operations Director }\end{array}$ \\
\hline PFashion & Clothing \& Retailing & Medium & Main & $\begin{array}{l}\text { E1-SCM Director } \\
\text { E2-Export Marketing Manager }\end{array}$ \\
\hline$U p b t$ & Clothing \& Retailing & Large & Main & $\begin{array}{l}\text { S1-SCM Specialist } \\
\text { S2-Export Manager }\end{array}$ \\
\hline Crisp & Food \& Beverage & Small & Main & $\begin{array}{l}\text { H1-CEO-SCM/Operations } \\
\text { H2-Deputy CEO-Marketing }\end{array}$ \\
\hline NoDrnk & Food \& Beverage & Medium & Main & $\begin{array}{l}\text { R1-Logistics Director } \\
\text { R2-Marketing Manager }\end{array}$ \\
\hline $\operatorname{TrdLrg}$ & Food \& Beverage & Large & Main & K1-Assistant CEO \\
\hline VsMnng & Mining & Large & Main & $\begin{array}{l}\text { P1-Export Marketing Manager } \\
\text { P2-Foreign Logistics Manager }\end{array}$ \\
\hline SarSt & Metal & Large & Main & L1-Procurement Director \\
\hline ElasPr & Automotive & Medium & Main & $\begin{array}{l}\text { O1-Procurement Manager } \\
\text { O2-Marketing \& Sales Director }\end{array}$ \\
\hline SAuto & Automotive & Large & Main & $\begin{array}{l}\text { M1-Procurement Engineer } \\
\text { M2-International Marketing Manager }\end{array}$ \\
\hline RvlAuto & Automotive & Medium & Main & $\begin{array}{l}\text { N1-Sales Manager } \\
\text { N2-SCM Director }\end{array}$ \\
\hline
\end{tabular}


Table 2. Exemplary evidence on demand and supply paradoxes

\begin{tabular}{|c|c|}
\hline $\begin{array}{l}\text { Demand and } \\
\text { supply paradoxes }\end{array}$ & Example quotes \\
\hline $\begin{array}{l}\text { Collaboration-- } \\
\text { Competition }\end{array}$ & $\begin{array}{l}\text { "Because we are a large company, we have a very complex organizational structure. Still, our functional boundaries } \\
\text { are blurry, and we all work together for overall success of our company. But, I can say that we are also in a sweet } \\
\text { competition with each other to achieve the best results for our functions"-S2, } \mathbf{U b t} \\
\text { "Marketing and SCM functions work together, and because we are not too big, these functions are well integrated } \\
\text { and inseparable. ... SCM is overwhelmingly strong in our firm and often has more say in determining our } \\
\text { company's strategy. So, we[marketing function] try our best to increase the power of marketing and have more } \\
\text { balanced relationships"-R2, NoDrnk }\end{array}$ \\
\hline Concord-Conflict & $\begin{array}{l}\text { "As I mentioned, different functions can stress and focus on different priorities. However, at the end of the day, } \\
\text { these conflicts are all solvable conflicts, because we [different functions] all know what the ultimate goal of our firm } \\
\text { is and have aligned key performance indicators"-S1, } \boldsymbol{U p b t} \\
\text { "We [two functions], not sometimes, but often are in conflict, because the SCM function does not have goals like } \\
\text { more sales. SCM function focuses more on overall cost reduction and also on supplier management. .. We are } \\
\text { reaching some concord concerning our goals. In fact, we are currently undertaking an initiative to establish aligned } \\
\text { KPIs"-O2, ElasPr }\end{array}$ \\
\hline $\begin{array}{l}\text { Integration-- } \\
\text { Differentiation }\end{array}$ & $\begin{array}{l}\text { "Our production function works almost as an independent company, and even can sell products to our competitors. } \\
\text {... Whenever we [two functions] have input, we stay in communication. Or, we jointly conduct R\&D activities, } \\
\text { especially concerning pricing and feasibility. After all, we have a serious integration."-Z1, CountCc } \\
\text { "As you may have noticed, different functions do different things separately in our firm, and eventually we may } \\
\text { have a mess.... Because we do not have segregation between functions, anybody can work together and stay in } \\
\text { communication"-T1, SVision }\end{array}$ \\
\hline
\end{tabular}


Table 3. Facing, managing, and transcending demand and supply paradoxes

\begin{tabular}{|c|c|}
\hline Themes & Example quotes \\
\hline $\begin{array}{l}\text { Theme 1: } \\
\text { Facing tensions } \\
\text { and resulting } \\
\text { anxiety and } \\
\text { ambivalence }\end{array}$ & $\begin{array}{l}\text { "It is exhausting to cope with the stress of performance. You have to control but also be flexible. You have to } \\
\text { innovate but also be efficient. You have to explore new strategies but also maintain your focus. It is very } \\
\text { stressful... These are not easy dilemmas. It feels muddy ("çamurda debeleniyoruz'). We cannot quite see where } \\
\text { we are headed. We are trying to solve the unsolvable."-P2, VsMnng } \\
\text { "I never understand why marketing people steal the show and get the rewards all the time while we are the ones } \\
\text { feeling the entire burden, costs, and the hard work."-O1, ElasPr }\end{array}$ \\
\hline $\begin{array}{l}\text { Corresponding } \\
\text { Literature: } \\
\text { (Lüscher \& Lewis, } \\
\text { 2008; Smith et al., } \\
\text { 2010; Vince \& } \\
\text { Broussine, 1996) }\end{array}$ & $\begin{array}{l}\text { "Supply chain people always try to push us towards cost reduction, and they see us as extravagant. In return, we } \\
\text { see them as thrifty and annoying. However, if we want to be vibrant, we have to go beyond our differences and } \\
\text { work together."-O1, ElasPr } \\
\text { "How can you make progress as an organization when every department is insisting on its own agenda and } \\
\text { interests? ('Herkes ayri telden caliyor'). We are sometimes trapped in vicious arguments and political battles. } \\
\text { Supply chain people are obsessed about cost reduction while marketing people seem to indulge in opulent } \\
\text { initiatives. Every group advances and defends their view. Whoever is stronger dominates; sometimes resulting in } \\
\text { grudges, future battles, and swings of power."-C2, SeaCom } \\
\text { "Marketing people sometimes impose impossible demands on our SCM people; while SCM people have } \\
\text { difficulty in grasping the absolute necessity of customizing or accelerating our operational practices for only one } \\
\text { strategic client"-IS3, VStyle }\end{array}$ \\
\hline $\begin{array}{l}\text { Theme } 2: \\
\text { Understanding and } \\
\text { accepting } \\
\text { paradoxes and } \\
\text { managing their } \\
\text { implications }\end{array}$ & $\begin{array}{l}\text { "We often have to work with two opposite goals. We want to be both efficient and innovative. We want to use } \\
\text { cutting edge technology, but we also use tech-free solutions that require better reflection and interpersonal } \\
\text { coordination... It is always between a rock and a hard place ('aşağ tükürsen sakal yukarı tükürsen blyık durumu } \\
\text { var.')...We want to satisfy our clients, but we do not want to lose money on them. In a way, we are constantly } \\
\text { struggling, balancing, and improvising."-T2, SVision } \\
\text { "We do not compromise or split between demand and supply activities. We are aware of the utility and } \\
\text { necessity of both types of activities."-E1, PFashion }\end{array}$ \\
\hline $\begin{array}{l}\text { Corresponding } \\
\text { Literature: } \\
\text { (Putnam et al., } \\
\text { 2016; Raza-Ullah } \\
\text { et al., 2014) }\end{array}$ & $\begin{array}{l}\text { "We are literally walking on a rope every day. You must be delicate to protect the balance. Of course there is } \\
\text { politics among departments. As a top manager, I play through tensions. I listen to both sides of a conflict and } \\
\text { agree with the relevant parts of both sides' arguments ("hem nalina hem mihina vuruyorum'). I am like Nasrettin } \\
\text { Hoca, agreeing with all sides and making sure all concerns are heard." -IS1, Icecom } \\
\text { "Initially we experienced some tensions as a dilemma across managerial functions. However, we realized that } \\
\text { we could never choose between competing tensions. Whichever alternative we choose, our choice intensified the } \\
\text { need for the other alternative."-M2, SAuto } \\
\text { "Actually due to the new newness of both marketing and SCM units, both units are trying to institutionalize their } \\
\text { practices while aiming for greater unity and collaboration. This is why we are struggling. I think it will take } \\
\text { about 5-6 more months to find common ground and establish aligned KPIs."-O2, ElasPr }\end{array}$ \\
\hline $\begin{array}{l}\text { Theme 3: } \\
\text { Ensuring } \\
\text { reflective practices, } \\
\text { communication, } \\
\text { innovative }\end{array}$ & $\begin{array}{l}\text { "The biggest takeaway is that you need regular consultation meetings where representatives from all departments } \\
\text { talk freely. We make sure that there is regular communication on sensitive issues such as the distribution of } \\
\text { resources or reward structures across units. These issues need to be discussed in a very open and transparent } \\
\text { manner to ensure justice and power balance among the units. We try to induce the feeling of unity under one } \\
\text { umbrella and equity in cross-functional relationships. We are part of the same family after all." -K1, TrdLrg }\end{array}$ \\
\hline $\begin{array}{l}\text { organizing, and } \\
\text { improvisation to } \\
\text { transcend paradox }\end{array}$ & $\begin{array}{l}\text { "[E]mployees in SCM and marketing units should rotate for a while to increase awareness of what the other } \\
\text { party does. I think it will eventually create synergy and contribute to our firm. Because, people need to } \\
\text { understand how the product is produced and what constitutes its cost components when selling these products." } \\
\text {-N2, RvlAuto }\end{array}$ \\
\hline $\begin{array}{l}\text { Corresponding } \\
\text { Literature: } \\
\text { (Melnyk et al., } \\
\text { 2010; Ozanne et } \\
\text { al., 2016; Smith \& } \\
\text { Lewis, 2011) }\end{array}$ & $\begin{array}{l}\text { "We immediately succeed through hardships, doing the impossible takes time (he giggles). We got a huge order } \\
\text { that needed to be delivered very urgently, and it required constant communication and coordination among } \\
\text { supply chain and sales departments. We said 'It is OK, no problem, we can handle this.' And we did it, thank } \\
\text { God. It is in our Turkish genes to perform well during last minute crises ('Yumurta kapiya dayaninca biz Turkler } \\
\text { harikalar yaratiriz')." -IS4, BscFd } \\
\text { "We need to manage and balance our cost and revenue structures simultaneously. We need to satisfy our clients } \\
\text { through innovative and cutting edge services, while being wary of our costs in offering such services. Marketing } \\
\text { and supply chain activities are two sides of the same coin. That is why we remove communicational and power } \\
\text { barriers across units and promote openness to new ideas and tolerance to conflicting views."-A2, BlogC }\end{array}$ \\
\hline
\end{tabular}

